\title{
A Life Plan Principle of Voting Rights
}

\section{Kim Angell ${ }^{1}$}

Accepted: 21 November 2019 / Published online: 9 December 2019

(C) The Author(s) 2019

\begin{abstract}
Who should have a right to participate in a polity's decision-making? Although the answers to this 'boundary problem' in democratic theory remain controversial, it is widely believed that the enfranchisement of tourists and children is unacceptable. Yet, the two most prominent inclusion principles in the literature - Robert Goodin's 'all (possibly) affected interests'principle and the 'all subjected to law'-principle - both enfranchise those groups. Unsurprisingly, democratic theorists have therefore offered several reasons for nonetheless exempting tourists and children from the franchise. In this paper, I argue that their attempts fail. None of the proposed rationales can do the job without having unacceptable implications for the voting rights of other groups. I then develop a new specification of the affected interests-view, one that avoids such problems. According to my life plan-principle, a person is entitled to participate in a polity's decision-making if and only if its decisions will actually affect her autonomously chosen life plans, or prevent her from developing or revising plans of that kind. I show that this principle straightforwardly avoids enfranchising tourists and children, and thus improves upon its two prominent rivals. The paper ends by considering and rejecting two objections to my new principle.
\end{abstract}

Keywords Voting rights · Boundary problem - Democratic theory Enfranchisement $\cdot$ All-affected · All-subjected $\cdot$ Life plans $\cdot$ Personal autonomy

\section{Introduction}

For any democratic form of government, laws are determined through a process that respects the will of 'the demos'. But how do we define the demos? The answers to this 'boundary problem' in democratic theory typically fall into two categories. According to the first, a person should have a say in a polity's decision-making ${ }^{1}$ if and only if its decisions affect her interests. Robert Goodin defends the arguably most prominent version of the affected interests-

${ }^{1}$ I use 'decision' to refer to both acts and omissions.

Kim Angell

kian@hum.aau.dk

1 Department of Culture and Learning, Aalborg University, Kroghstræde 3, 9220 Aalborg, Denmark 
view. According to his all (possibly) affected interests principle (AAP), voting rights should be distributed to "all interests possibly affected by any possible decision under any possible agenda" (2007: 55). AAP is extremely inclusive: tearing down "boundaries both of space and time", it proposes that "[v]irtually (maybe literally) everyone in the world - and indeed everyone in all possible future worlds - should be entitled to vote on any proposal or any proposal for proposals" (2007: 55). According to the other category, a person should have a say in a polity's decision-making if and only if she is subjected to them. Claudio López-Guerra defends a typical version of this view. According to his all subjected (to law) principle (ASP), "anyone who is subject to the laws of a democratic polity should be included in the citizen body" (2005: 221). ${ }^{2}$ For López-Guerra, a person is subjected only if the relevant laws can be coercively enforced against her. In a system of territorially defined sovereign states, this means that states only subject people within their respective territories. ${ }^{3}$

Although AAP and ASP have become prominent in the literature, they fail to support what many regard as the intuitively correct pattern of enfranchisement in two hard cases. As we shall see, AAP and ASP both imply that tourists and children are entitled to vote. Because democratic theorists widely share the intuition against enfranchising those groups (Whitt 2017: 296), they need to find "exceptions to the rule [which] may be independently justified" (Whitt 2017: 293). ${ }^{4}$ In this paper's first main part, I argue that several recent attempts to justify exceptions for tourists and children are unsatisfactory. In addition to being more or less ad hoc, the proposed rationales have unacceptable implications for the voting rights of various other groups. In the paper's second main part, I develop and defend a refinement of the affected interests-view that avoids these problems. According to my new principle of voting rights, a person is enfranchised on a polity's decision if and only if that decision will affect her autonomously chosen life plans or prevent her from developing or revising plans of that kind. I shall refer to this inclusion principle as the life plan principle (LPP). ${ }^{5}$

As I understand them, AAP, ASP and LPP give alternative accounts of a normative ideal. They purport to provide a fixed point against which different practical decision methods might be critically assessed in accordance with how well they approximate that ideal (Arrhenius 2005: 4-5). Following a common view, I take the relevant ideal to be democratic legitimacy; unless a decision is made by a demos constituted according to the relevant principle, that decision is democratically illegitimate. ${ }^{6}$

The paper unfolds as follows. Sections 2-3 show that AAP and ASP, as their proponents have thus far developed them, must either counterintuitively enfranchise tourists and children,

\footnotetext{
${ }^{2}$ For similar versions, see Beckman (2009: 47-50), Owen (2010), Erman (2014), Whitt (2017).

${ }^{3}$ Some ASP-proponents controversially reject this enforcement-requirement. For them, exposure to a state's coercive threats is sufficient for subjectedness. Border laws, e.g., might thus subject extraterritorially (Abizadeh 2008).

${ }^{4}$ It is common to treat pre-theoretical considered judgments, or 'intuitions', about more or less imaginary cases as relevant input when assessing normative principles. When a principle's implications fit our intuitions, this gives pro tanto support for it, and vice versa. Proponents of AAP and ASP generally follow that method, and I shall do the same. That is arguably justified, as I aim to assess AAP and ASP on their own terms, and to defend a principle that improves upon them. Although the use of moral intuitions is arguably inevitable in political philosophy (Elster 2011), it is controversial whether they are truth-apt.

${ }^{5}$ I presently bracket the questions of what kind and amount of influence that a relevantly affected person should have (Arrhenius 2018: 104-108). I assume that influence refers to voting rights. Moreover, I take no stand on whether a person's amount of influence corresponds to her degree of affectedness. I intend my analysis to be compatible with weighted and unweighted versions of LPP. For an analysis of affected interests-views and weighted voting, see Brighouse and Fleurbaey (2010).

${ }^{6}$ See e.g. Abizadeh (2008), Owen (2012), Miklosi (2012), Lampert (2015), and Whitt (2017).
} 
or allow similarly counterintuitive results for the voting rights of several other groups. In Sect. 4, I put forward my new specification of the affected interests-view. I first expose LPP's normative foundation in a widely recognized value: personal autonomy. I then explicate key parts of LPP's formulation. This includes showing (in Sect. 5) why LPP avoids the extreme inclusiveness of AAP - a feature that many regard as a reductio of the latter (Goodin 2016: 367-368). Section 6 shows how LPP is able to accommodate our intuitions about tourists and children in a non-ad hoc manner. That ability, however, might come at a price. In order to exclude tourists and children, I made LPP significantly more restrictive than AAP, and that might risk pushing LPP towards under-inclusiveness. Section 7 considers and rejects an objection along such lines. Section 8 addresses a different worry: that LPP's enfranchisement patterns might accentuate socioeconomic injustice. The paper ends with a conclusion.

\section{AAP and ASP on Tourists}

To clarify what AAP and ASP imply for the enfranchisement of short-term transients, consider

The Tourist: Donald, a US citizen, is on a short vacation in Mexico, where he is enjoying the bars, restaurants and beaches of Cancun. In a few weeks, he will travel back to the US.

Should Donald have a say over the Mexican laws that apply to him during his vacation? The common intuitive response is presumably negative. That answer, however, sits uncomfortably with AAP. After all, Donald is clearly affected by laws regulating the opening hours on restaurants and bars, the maintenance of beaches, etc. If so, AAP will enfranchise him on such policies. Moreover, insofar as the laws regulating virtually any other policy area will also possibly affect his interests, AAP would give him a say on those as well. From AAP's viewpoint, Donald's general say on Mexican decisions is solid.

The inclusion of tourists is widely thought to follow also on ASP: whenever a person is present within a polity's territory, she is subject to its legal system; if subjectedness grounds enfranchisement, tourists should be entitled to vote (Bauböck 2009: 480; Beckman 2009: 82). Some ASP-proponents, however, have sought to challenge that implication. According to López-Guerra, tourists "can be rightfully excluded since they would otherwise be electing decision-makers whose resolutions would not be binding on them later" (2005: 226). That reply is insufficient. It cannot explain why ASP does not simply enfranchise tourists prior to their arrival - giving them a say over laws that will subject them when they arrive.

In a recent work, López-Guerra tries a different response. To avoid enfranchising tourists, he qualifies ASP as follows: to be enfranchised, a person must be "regularly subject to the legal system of a political unit" (2014: 97). The rationale behind this qualification is that "even though tourists are subject to the legal system of the polity they visit, their lives are not governed by it" (López-Guerra 2014: 98). Citing a similar reason for "exempting short-term resident non-citizens from the all-subjected principle", Matt Whitt writes that transients "are not subject to the laws of the land in the same way as citizens and long-term residents, whose lives - and not merely their travels - are governed by the laws on an ongoing basis" (2017: 297). If we interpret this proposal literally, the idea here seems to be that a person's enfranchisement depends upon the extent to which the state's laws influence, or 'govern,' how she leads her life. Call this the differential-life-governance-proposal. 
I doubt that the differential-life-governance proposal will be satisfactory for ASP-proponents. Note first the ambiguity involved in having one's life 'governed' by a set of laws. A polity's laws typically govern a person's life both positively and negatively. It governs positively by providing her with certain opportunities which would be unavailable without those laws (e.g. paid parental leave, affordable student loans, etc.), and which she may or may not prefer pursuing. Negatively, the laws govern a person's life by constraining access to options she may want to pursue but which the law forbids (e.g. withholding taxes, jaywalking, exacting blood revenge, etc.). The opportunity-side of the equation arguably imposes the exact same degree of 'governance' on persons A and B insofar as they qualify for the same public benefits (regardless of A's and B's preferences for making use of them). On the negative side, however, the law seems to 'govern' A's life relatively more than B's, simply if it forbids more of A's preferred options than it does B's, all else being equal. On this understanding of 'governance', it becomes unattractive to qualify ASP according to the differential-lifegovernance variable. ASP would then imply that people with criminal intent have a stronger claim to the franchise than people who feel no urge to break the law, all else being equal. After all, the former's lives are relatively 'more governed' by the law because a larger part of their behavioral preferences are frustrated.

The differing-life-governance proposal also risks inadvertently expanding the franchise across territorial borders. That would be unwelcome for ASP-proponents, who typically applaud ASP's alleged ability to avoid extra-territorial expansion of the franchise (Whitt 2017: 293; see also Goodin 2016). However, if ASP (in its modified version) enfranchises people according to the law's effect on how people conduct their lives - not according to whether it purports to bind them - it is unclear why we should measure those effects only within the polity's borders. It seems descriptively accurate that a polity's laws typically 'govern' the lives of non-transients relatively more than the lives of transients. The lives of permanent residents in Miami are generally, to use Whitt's phrase, more "constrained by the coercive power of the [US]" (2017: 298), than a German tourist visiting South Beach for a week. However, if the crucial difference between them is how US laws constrain how they lead their lives, one might wonder why large numbers of Cubans, Mexicans, and others (around the globe), should not be enfranchised in US decision-making. The differential-lifegovernance-proposal is unattractive for ASP-proponents.

But perhaps we could interpret the López-Guerra-Whitt proposal differently. On an alternative reading, what matters is simply how long you are subjected to the state's laws, regardless of the extent to which those laws influence how you live. Call this the temporalsubjection-proposal. On the temporal-subjection-proposal, ASP may clearly disenfranchise tourists in many cases. After all, very many of a state's laws have long-term application, and will continue to subject the state's residents for years after a short-term tourist has left its territory. If we require, say, one-year-subjection to a law for a person to have a say on it, this will disenfranchise most tourists in practice. However, we can easily imagine cases - of shortterm decisions - where the temporal-subjection-proposal cannot avoid counterintuitively enfranchising short-term transients. Consider the following modified Donald-example:

Mexican Referendum: As it happens, Donald's visit to Cancun coincides with a peculiar referendum. After discovering electoral irregularities, the Mexican National Electoral Institute has scheduled a new election shortly. In the meantime, the referendum asks whether policies passed after the fraudulent election should be immediately declared null 
and void - thereby reinstating old laws - or whether they shall remain in effect until the new election is held (say, in three weeks).

In this example, Donald stays in Mexico (or so we may assume) for the full duration of the decision's application. Because the referendum decision thus subjects him in the exact same way as it subjects any resident Mexican, ASP enfranchises them both. Yet the counterintuitiveness of giving him a say presumably lingers on.

Apart from counter-intuitive results in cases of short-term decisions, the temporalsubjection-proposal faces the challenge of identifying a threshold of sufficient temporal subjectedness for longer-term decisions. For one thing, it is hard to see how such a threshold can be identified non-arbitrarily. Moreover, regardless of where we make the cutoff, cases of counter-intuitive exclusions and/or inclusions - above or below the threshold - will presumably be rife. The temporal-subjection proposal seems highly problematic.

Some believe that our intuitions about tourists might change if we reject a strictly dichotomous voting-scheme. Rather than distributing the franchise such that people have equally weighty votes or none at all, we could give tourists a partial say in a weighted voting-scheme. David Owen believes that this solves ASP's tourism-challenge. Owen starts by conceding the initial problem:

[I]t is simply counter-intuitive to include transients in the demos as political equals alongside non-transients whose subjection to the decisions of the polity is (in certain respects at least) more consequential in virtue of being of greater temporal duration as well as, typically, more encompassing with regard to the various dimensions of their life (2012: 146, my emphases).

He then claims that the counter-intuitiveness of enfranchising transients "dissolves" if we give transients less voting power than non-transients. According to Owen, this can be done by weighting a person's voting power in state $\mathrm{S}$ according to "the scope, degree and temporal extent of [her] subjection" to S's laws (2012: 147). However, if ASP incorporates a weighted voting-scheme along the lines of Owen's proposal, this will produce various counterintuitive results in other domains. Note first that two of the variables Owen offers - 'scope' and 'degree' - are problematic as indicators of differential subjectedness. For reasons already given (in my discussion of the 'differential-life-governance' proposal), they will have unacceptable implications for the voting rights of various other groups (e.g. by decreasing the voting power of law-abiding individuals compared to those with criminal intent, all else equal). This leaves 'temporal duration' as the only potentially plausible basis for voting weight differentiation in Owen's proposal.

If ASP incorporates a time-sensitive criterion, it might straightforwardly ascribe more voting weight to non-transients. ${ }^{7}$ However, this modified version of ASP would produce counterintuitive results for sub-groups of non-transients in other cases. For example, all else being equal, it would imply that non-transient women, due to their longer life expectancy, should generally have weightier votes than non-transient men should. If we find such upshots unacceptable, Owen's proposal is not a satisfactory solution to the problem of counterintuitively enfranchising transients (on equal terms with non-transients). A scheme that weights

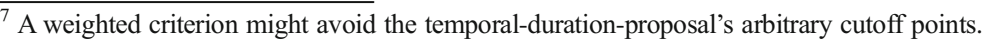


votes according to the duration of people's subjectedness might well create more problems than it solves.

\section{AAP and ASP on Children}

Let us now explore what AAP and ASP imply for the enfranchisement of minors. Consider

The Child: four-year old Louise likes cars. She wants to obtain a driver's license and to earn enough money to buy a vehicle. According to the law, however, she is too young both for driving and wage-labor. Louise disapproves. She wants the rules to change.

Be that as it may. It is nonetheless counter-intuitive to enfranchise small children like Louise, even on these two policy areas only. AAP would disagree, though. Louise's interests are clearly affected by the relevant laws, and she is therefore enfranchised on them. Moreover, because we may presumably construe virtually any law as having possible effects on her interests, AAP would even enfranchise Louise in general elections.

ASP has the same implication. Like other residents, Louise is subjected to the laws of the polity under which she lives. According to one influential democratic theorist, the upshot is that Louise's "right to vote in the democratic process" follows from ASP "for exactly the same reason as the right to vote for adults does" (Beckman 2009: 99). Not surprisingly, many ASPproponents have sought to exempt (at least very young) children from the franchise. Speaking of "a two-year old child" and "a person with severe brain-damage", López-Guerra invokes a competence-rationale in order to explain why they should not be allowed to vote: such people are "incapable of understanding what an election of representatives is about" (2005: 226). Now, although imposing a competence-requirement might well be independently plausible, it is unclear how it follows from ASP itself. In Ludvig Beckman's view, himself an ASPproponent, such a rationale would clearly be in 'tension' with the principle (2009: 119). Assuming arguendo that the competence-requirement is at least compatible with ASP, it is still unclear why invoking it is not simply an ad hoc solution. Having to resort to ad hoc hypotheses is not, I believe, a decisive problem. However, in general, such moves arguably reduce a view's overall plausibility. ${ }^{8}$

Matt Whitt, another ASP-proponent, mentions an exemption-rationale with a less ad hocflavor: a reason for why "children are typically exempted from the all-subjected principle" could be that "they are not subject to the law in the same way as adults (their legal obligations differ)" (2017: 296). Whitt does not elaborate this 'differing obligations'-rationale. To assess it we therefore need to consider some alternative readings. First, the legal obligations of children and adults might differ in that children have only negative obligations (to refrain from certain actions, e.g. shoplifting), whereas adults also have positive obligations (to perform certain actions, e.g. paying taxes). On this version, the differing obligations-rationale would counterintuitively imply that unemployed people have relatively weaker claims to enfranchisement than those who pay income taxes, all else being equal. On a second interpretation, what generally distinguishes children from adults is that children have fewer legal obligations. Nevertheless, it is difficult to see how we could make such a cut without, again, generating unattractive inequalities between adults. If we differentiate people's voting rights based on

${ }^{8}$ They do so by reducing its syntactic simplicity (Baker 2016). 
their number of legal obligations, this implies, for example, that able-bodied workers have stronger claims to voting rights than severely handicapped persons who have no legal obligation to pay income taxes, all else being equal. As before, our intuitions, I take it, reject such upshots. A third interpretation is that children are not prosecutable for breaches of legal obligations whereas adults are. That idea might seem promising. After all, in most countries criminal responsibility does not start until (early) adolescence. However, a state's laws contain much more than its criminal code. It is hard to imagine a (morally defensible) set of laws where children enjoy no legal rights, for example. Whenever they have such rights, the laws specifying them do apply to the children, and ASP implies granting them a say in their making. So, insofar as Whitt's aim, as he writes, is to explain why children are 'exempted' from ASP (not merely partially disenfranchised), appealing to differing criminal responsibility is insufficient. The differing-obligations-rationale fails.

It is time to take stock. Our analysis has thus far shown that AAP and ASP run counter to our intuitions about the enfranchisement of tourists and children, and that several recent attempts to exempt these groups are unsatisfactory. The exemption-rationales cannot avoid creating unattractive results in other domains. Without claiming that this critical analysis is conclusive, I now turn to a more constructive task. In what follows, I aim to develop and defend an alternative inclusion principle that overcomes these problems.

\section{A New Specification of Affected Interests: The Life Plan Principle}

According to the

Life Plan Principle (LPP): A person is entitled to participate in a polity's decisionmaking if and only if its decisions will actually affect her autonomously chosen (actual and central) life plans, or prevent her from developing or revising plans of that kind.

LPP rests upon the belief that being the author of one's own life is morally important. ${ }^{9}$ Personal autonomy is the more fundamental value which explains why people have a weighty interest in influencing decisions which affect their (ability to freely develop, revise or sustain) projects and pursuits. Many believe that the value of personal autonomy may plausibly justify democratic governance itself (Waldron 2012: 195-196). ${ }^{10}$ I shall remain agnostic on that issue. My present concern is how the value of personal autonomy may help identify the boundaries of the demos.

There are three necessary and jointly sufficient conditions for personal autonomy. ${ }^{11}$ First, a person must have sufficient internal capacity for autonomy, in the form of certain mental abilities to draw upon when making her choices. An autonomous person is capable of rationally fitting means to ends. Moreover, she is capable of reflecting critically upon her options, and of making her choice in light of her 'own viewpoint'. As one writer puts it, she must "have attitudes that manifest her own evaluative outlook" and be able "to guide herself in

\footnotetext{
${ }^{9}$ I presently assume the moral importance of autonomy. For a defense, see Raz (1986).

${ }^{10}$ Others believe that, although a person's interest in autonomy may be decisive in various private matters (where it is possible for her to be sovereign), this is not transferable to democratic decisions, because no single voter can be sovereign in irreducibly collective decisions whenever preferences among the electorate differ (Christiano 1996: 19).

${ }^{11}$ Here I largely follow Raz (1986: 154-155; 372-378).
} 
light of these attitudes over time" (Betzler 2015: 69). ${ }^{12}$ Second, she must have sufficient external capacity for autonomy, in the form of an adequate (i.e. varied and meaningful) range of options from which to choose. Third, once her autonomous choices are made, she must be permitted to pursue them without interference. If one or more of these conditions are breached, autonomy is not preserved. Respect for autonomy's three conditions is reflected in LPP. LPP enfranchises a person on a polity's decisions whenever they affect her autonomy. This can happen because the laws affect her autonomously chosen plans (the third condition) or prevent her from acquiring or sustaining the capacity to make and revise such plans - by hampering her mental abilities (the first condition) or by restricting her access to an adequate set of options (the second condition).

There are two constraints on the type of plans covered by LPP. First, LPP enfranchises people on decisions that affect plans they actually have. Possible plans - plans that people could have endorsed, but which they nevertheless are not committed to when the political decision is made - do not count. The reason for this constraint is that non-interference with a person's possible plans is not required to preserve her autonomy. For most people, option sets change continuously. This may be due to "social, economic and technological processes [which] are constantly changing the opportunities available in our society" (Raz 1986: 411). If a particular opportunity is eliminated, the effect is much more serious for people who are already committed to that opportunity:

[D]enying a person the possibility of carrying on with his projects [...] is preventing him from having the life he has chosen. A person who may but has not yet chosen the eliminated option is much less seriously affected. Since all he is entitled to is an adequate range of options the eliminated option can, from his point of view, be replaced by another without loss of autonomy (Raz 1986: 411).

So, concerning the importance of non-interference (the third condition), the life plans that matter for preservation of autonomy, and hence for LPP, are the plans people are actually committed to. Possible commitments are irrelevant.

The second constraint is this. LPP enfranchises people only on decisions affecting their autonomously chosen central life plans (or their ability to develop and revise plans of that kind). Plans qualify as central in our lives if they "organize many choices, and are fundamental to our sense of our lives as our own"; this sets them apart from our 'everyday choices', which we make "in part because they contribute to the achievement of more abstract, pervasive [i.e. central] aims" (Stilz 2013: 336-337). Like the first constraint, the rationale for this centralityconstraint is found by considering LPP's foundational value. As Raz makes clear, a person's autonomy is only interfered with when she is prevented from developing and pursuing "pervasive goals, projects or relationships" (1986: 409-410). For example, while a person's autonomy is clearly diminished if she is denied the option of having an education, the same is not true when a certain brand of ice cream is made unavailable to her. Although a person may prefer to eat a particular ice cream brand, doing so is (typically) not central, or 'pervasive', enough in her life for its unavailability to raise concerns about violation of autonomy.

It is worth underlining that, on my account, a plan might be central without having long duration. For some theorists, a 'life plan' refers to a fully worked out long-term scheme,

$\overline{12}$ This account of internal capacity is deliberately rough, because I intend LPP to be compatible with various views. For an overview of the debate, see Buss and Westlund (2018). 
identifying the best path through a structurally complex set of all foreseeable choice-situations that a person might encounter during her whole life (Rawls 1999: 358-361). I have no such grandeur in mind. From LPP's viewpoint, the moral significance of life plans flow from the value of personal autonomy. An autonomous person might sometimes simply change her mind, act out of character, or even decide to live without long-term plans whatsoever. ${ }^{13}$ As Raz writes, "[p]eople usually control their lives not by deciding once and for all what to do for the rest of their lives. Rather they take successive decisions, with the later ones sometimes reversing earlier decisions, sometimes further implementing them, and often dealing with matters unaffected by the earlier decisions" (1986: 374, n. 1). As a rule of thumb, aside from the two constraints I have mentioned, what matters for LPP is how a person chooses her plans, not what content she gives them.

Note also that, although development of and changes in life plans might typically be gradual (with more significant changes presumably requiring relatively longer time-spans), there is no necessity about this. A person could experience a sudden and radical change in how she wants to lead her life. She might decide, for example, to change her professional career overnight. If so, several political decisions that were once immaterial to her life might suddenly become crucially important for her new projects. ${ }^{14}$ Others might no longer affect her at all. LPP tracks these developments - giving her a say on all and only those political decisions that affect her (ability to live a) self-chosen life.

\section{Two Crucial Differences Between LPP and AAP}

As mentioned, Goodin's AAP is extremely inclusive. Apart from enfranchising tourists and children, it identifies virtually global demoi for almost any decision taken anywhere. Most find that inclusiveness strongly counterintuitive. I have therefore aimed to make LPP much more restrictive. Two crucial differences between LPP and AAP help me achieve this. First, while AAP seems to include any interest, LPP only refers to people's interest in leading an autonomous life. In fairness to Goodin, he writes that AAP might need various "fine-tunings" before it is applied. These will "perhaps" include differentiated voting weights in proportion to the degree to which people's otherwise similar interests are affected, and a ranking of interests in accordance with their moral importance (Goodin 2007: 51). Yet, he does leave AAP unspecified in these respects.

We could try to second-guess which restrictions on relevant interests Goodin might favor. However, regardless of where he would draw the line, those restrictions will presumably have little if any effect on AAP's inclusiveness. The reason is that AAP, as we have seen, enfranchises all possibly affected interests. This feature is the second important difference

\footnotetext{
${ }^{13}$ An anonymous reviewer asks whether LPP may enfranchise people who lack the "well-structured, hierarchically organized [Rawlsian] scheme", yet have "several smaller-scale ambitions", or simply are "drifters without any clear direction or shape to their lives". LPP normally enfranchises such people, at least on various decisions. Imagine a person who has chosen to organize her life for, say, no more than six months ahead. Whatever she plans to do during that period, it is presumably affected if her landlord can evict her overnight without notice. Unless she (outlandishly) plans to be dogged around by whatever decisions others make, LPP will give her a say on the state's tenancy laws - and presumably many others. (Policy-interconnectedness might also expand her enfranchisement. See Sect. 7.)

${ }^{14}$ This relation between the passage of time and life plan-based enfranchisement sets LPP apart from the ASPrelated 'temporal-duration-proposal' considered in Sect. 2, where a person's enfranchisement is a simple function of how long she is subjected to the law.
} 
between AAP and LPP. LPP only enfranchises actually affected interests. If it were to replace 'actually' with 'possibly', LPP would collapse into AAP. LPP's more restricted account of relevant interests would then make little difference for the following reason. It is arguably conceivable that whatever decision made by whichever polity will possibly affect the relevant life plans (or the ability to make and revise such plans) of virtually anyone anywhere. As long as we make the causal chain long enough and consider all possible worlds, that upshot seems unavoidable. But if this is true for a 'possibilistic' formulation of $L P P$, it presumably means that AAP would imply global enfranchisement regardless of any restrictions Goodin might introduce to his theory's account of relevant interests. The key to AAP's extreme implications is its possibilistic formulation, not its (more or less restrictive) account of relevant interests.

Before moving on, let me address an apparent objection to the kind of 'actualistic' formulation I favor. The idea is that actualistic affected interest-views are incoherent for the following reason. In order to know whom to enfranchise on a decision, we must first know who will actually be affected by its outcome; and we cannot know the outcome prior to the decision. In Goodin's words, an actualistic principle "is unable to tell us who is entitled to vote on a decision until after the very decision has been decided" (2007: 52). However, this objection overlooks the distinction between being affected by the outcome and by the choice situation itself. In order to determine whether people's interests are affected by a decision between options $\mathrm{O} 1, \mathrm{O} 2$, and $\mathrm{O} 3$, it is sufficient to establish that their interests will be affected by the choice of $\mathrm{O} 1$, or $\mathrm{O} 2$, or O3. As David Owen puts it, "[h]ow their interests will be affected cannot be determined prior to the outcome, but that their interests will be affected in one way or another can be determined before the outcome is decided" (2012: 133; see also Arrhenius 2018).

Although Owen's reply is fine as far as it goes, it cedes a lot of ground to Goodin's incoherence-objection. Goodin objects to actualistic affected interests-views by claiming that they cannot (logically) work as formulas for devising a practical decision-method. Owen replies by demonstrating that they can. He shows that there is no logical contradiction involved in using the affected interests-view for that purpose. However, I think there is another, more fundamental, rejoinder to Goodin's objection. That rejoinder denies that actualistic affected interests-views aim to devise a practical decision-method in the first place. We may understand AAP, ASP and LPP as candidate formulations of a normative ideal (e.g. the ideal of democratic legitimacy). They provide us with a yardstick for evaluating practical decisionmethods in terms of how well they approximate that ideal. If so, Goodin's objection is misguided. It equivocates on the distinction between principles as ideals and principles as practical decision-methods, and holds actualistic affected interests-views to a 'practicability'standard that they do not intend to meet. Moreover, Goodin does not hold his own AAP to the same standard. He clearly regards AAP as a normative ideal, not a decision-method blueprint. As he writes, AAP might well be "wildly impractical", so "we need to begin thinking what arrangements might best approximate that ideal in some practice that is feasible" (2007: 64).

There might be various epistemic challenges related to determining whether a person's interest in personal autonomy will actually be affected by a specific choice situation. Before we can be sure about having enfranchised the correct set of people, we might have to wait until the decision is made - by a potentially incorrect demos. However, that does not undermine LPP as an ideal. It only means that when we implement LPP, we will normally have to accept some uncertainty about whether our practical decision-method fully approximates that ideal principle. Sometimes we might predict quite well. Other times we might not. The ideal nonetheless remains the same. 
To be clear, I am not claiming that it is irrelevant, for the general evaluation of ideals, to what extent an ideal's implementation is practically difficult. Taking a stand on that topic falls outside this paper's scope. Let me only note that it is not merely actualistic affected interests-view (like LPP) which might have a hard time determining the exact boundaries of the ideal demos in practice. Even AAP can be expected to face difficult epistemic challenges. Unless it is always the case that anyone is possibly affected by any decision, AAP must distinguish between those with and those without possibly affected interests. And it is presumably very difficult to draw the exact line between those groups in practice. This suggests that practicability arguably favors none of the said inclusion principles in particular, regardless of the importance we ascribe to that desideratum. ${ }^{15}$

To sum up, my version of the affected interests-view recommends significantly less inclusive enfranchisement patterns than AAP. Two features of LPP secure this result. First, and most importantly, I formulated LPP in actualistic terms. Second, I restricted the set of relevant interests to people's interest in personal autonomy, which further reduces LPP's inclusiveness. We may now assess whether LPP disenfranchises the two groups who caused problems for AAP and ASP.

\section{LPP on Tourists and Children}

LPP straightforwardly excludes Donald in The Tourist and Mexican Referendum. The relevant decisions do not affect his actual and central life plans nor prevent him from autonomously reordering his life. LPP implies the same for tourists generally. Imagine that Norway closes its borders for travelers. Although Norway is a decent tourist spot, that decision is no life changer for those who no longer have the option of marveling at the midnight sun, or enjoying (if that's the right word) the infamous 'lutefisk' in its traditional surroundings. For those who had not yet planned to visit Norway, removing that option from the feasible set is no threat to their external capacity for autonomy. Other interesting places abound. For those who had already planned a trip to Norway, going there is presumably not a central part of their life plans. For most, their pursuits may continue in all significant respects. According to LPP, those tourists have no say in Norwegian (tourism) decisions. However, there is a tipping point here. Imagine a German tourist who becomes enamored with Lofoten, and plans to visit ever more frequently and for longer periods each time. Her central life plans start to revolve more and more around her activities in this part of Northern Norway. At some point, her autonomously chosen projects have become equally divided between Germany and Norway. In this case, LPP may enfranchise her in both states. (She would be enfranchised not only on tourism decisions, of course, but also on other decisions affecting her life in the two countries.) Over time, the scales might tip, such that her plans start to revolve more dominantly around one place. Consequently, she might be disenfranchised in the other. ${ }^{16}$

\footnotetext{
${ }^{15}$ ASP also faces such practicability-concerns. Consider, e.g., the difficulty of predicting who exactly will visit a polity as tourists, whether current demos-members will move abroad or die before the laws they have authored are implemented, etc. Those challenges are presumably as daunting as those facing affected interests-views.

${ }^{16}$ Note what this implies for expatriates. For LPP, expatriates might retain their right to participate in the decisions of the country they have left. Like the German in Lofoten, this depends upon whether they retain plans affected by those decisions. In contrast, ASP is typically believed to categorically disenfranchise expatriates (López-Guerra 2005), while AAP includes them on a (much) wider range of decisions than LPP. An anonymous reviewer mentions another interesting case: "migrants who, due to the EU Dublin agreements, are indefinitely stuck in a European country when their goal was to reach another country". LPP enfranchises them on all and only those decisions that affect their life plans (including the Dublin policy itself). In comparison, AAP and ASP enfranchise them on a wider range of laws.
} 
LPP's implication in The Child is also straightforward. Louise's plans - to obtain a driver's license and a wage-paying job - fail to trigger LPP. The reason is that Louise does not (yet) possess sufficient internal capacity for autonomy. In her case, the laws affect no autonomously chosen life plans. Such plans do not yet exist. I intend that characterization of Louise to be uncontroversial. As Amy Mullin writes:

One of the most important factors someone must have in order to act autonomously is experience relating to the particular domain where autonomous action is called for. Children [between three and eight] often lack relevant forms of knowledge and experience. They also typically lack the ability to understand and appreciate the long-term effects of their decisions [...] (Mullin 2007: 549).

It is hard to deny Mullin's description. Although internal capacity comes in degrees and develops gradually (Rehfeld 2011), four-year old children are typically (far) too lacking - both in means-end rationality and (especially) in critical reflection - to qualify as autonomous. This presumably holds regardless of where the threshold for sufficient capacity is (plausibly) drawn. Louise is disenfranchised.

If it turns out that older children (e.g. ten-year-olds) are sufficiently autonomous, concerning at least some political decisions, LPP enfranchises them on those decisions. ${ }^{17}$ Personally, I am happy with that result. My present concern is merely to show that LPP has a non-ad hoc explanation for why small children (like Louise) should remain disenfranchised, while AAP and ASP do not. ${ }^{18}$ The latter will regard children as relevantly affected or subjected - and hence as enfranchised - regardless of their age.

I conclude that LPP straightforwardly explains our intuitions about tourists and (at least small) children. Their disenfranchisement follows from LPP's foundation in the value of personal autonomy. The necessary and jointly sufficient conditions for living an autonomous life yield a suitably restrictive account of relevant affectedness. However, although LPP's restrictiveness towards tourists and children might give it an edge over AAP and ASP, let us now consider the opposite worry: whether it includes too few in other cases.

\section{Under-Inclusion: (Too Many) ‘Non-Autonomy-Affecting’ Decisions?}

Some laws routinely made by democratic states might seem to have little if any effect on people's autonomy. Whether we drive on the left or the right side of the road, for example, is apparently irrelevant for autonomy. LPP identifies no principled demos for truly 'non-autonomy-affecting' decisions. Some might regard that as an unattractive result (one whose unattractiveness presumably increases with the number of such decisions, all else being equal).

In reply, let us first clarify the objection. It cannot concern theoretical inconsistency. The objection cannot be that LPP fails to identify a demos for decisions which - from the principle's own perspective - do not engage the interests that ground enfranchisement. That would hold for any inclusion principle. The objection is rather that: it is counter-intuitive not to

\footnotetext{
${ }^{17}$ According to López-Guerra (2012: 136-137), "the best available evidence on moral and cognitive development" indicates that ten-year olds are typically capable of understanding "the idea of electing representatives and to adopt a position of their own, however rudimentary, on [...] the alternatives at a given contest".

${ }^{18}$ LPP has similar implications for adults with intellectual disabilities. Their enfranchisement depends upon their having sufficient internal capacity for autonomy.
} 
enfranchise people on non-autonomy-affecting decisions. Personally, I do not share that intuition, and am happy to accept the relevant implication. But let us set that aside, and instead consider three reasons to expect that states will typically make very few, if any, truly nonautonomy-affecting decisions. If correct, that should largely dissolve the alleged problem.

First, if the state's inhabitants have developed their ways of life within a somewhat stable legal framework over time, it seems difficult to find decisions that do not affect the life plans of at least some people. Imagine that the UK decides to harmonize their long-standing traffic rules with the rest of the world. As part of this policy, people are required to scrap their old cars in favor of new (subsidized) ones suitable for driving on the right. This apparently nonautonomy-affecting decision would interfere with the central life plans of at least some people. Passionate veteran car owners, for example, could no longer take their beloved cars for a spin, and LPP would enfranchise them on the decision.

Second, in a modern large-scale state, the passing of any single law typically influences the application of other existing laws, or the prospects for passing new ones. If the UK passes the traffic harmonization-law, it must spend significantly on infrastructure modification and car subsidization. Because those funds must come from somewhere, the traffic law-decision significantly influences decisions within other sectors of UK society (e.g. health care or education). It is easy to imagine that the number of people relevantly affected by those decisions far exceeds those (few veteran car owners) directly affected by the traffic lawdecision itself. Consequently, due to the interconnectedness of various policies, we can expect LPP to identify a significantly broader electorate on a decision that initially appeared to engage the autonomy of relatively few. Presumably, a similar analysis is applicable to most of the decisions made by democratic states.

Third, we may often regard policy decisions from several perspectives. At one level, the traffic harmonization-decision is a merely practical one, concerning which side of the road to use. However, it could also be seen as concerning the proper relationship between the UK and Europe, where a decision to scrap left-side driving may influence British identity. Many believe that individuals have autonomy-based reason to care about the development of the collective identity of groups to which they belong (Miller 1995). Insofar as individuals care about such developments, LPP may enfranchise even larger numbers on the traffic lawdecision.

Clearly, all this depends upon empirics - upon how much policy A influences the passing of policy B, whether a person has developed this or that life plan, etc. Settling such issues is beyond this theoretical article's scope. However, even on moderate empirical assumptions, we might push back quite significantly on the present objection. In practice, there will presumably be few, if any, political decisions that have no effects on personal autonomy.

\section{Transmitting Injustice?}

Let us end by considering a more fundamental challenge to LPP. LPP (like affected interestsviews generally) enfranchises anyone whose relevant interests are affected by political decisions. The problem is that the distribution of interests might be shaped by unjust factors. Take a superrich person whose luxury lifestyle constantly brings her around the world. Due to her plans' global reach, she is enfranchised in many more countries than regular people are. Assuming that socioeconomic inequalities of this magnitude are unjust, LPP implausibly 'transmits' socioeconomic injustice into the political domain. 
In response, note first that the objection - regardless of its merits - does not merely apply to affected interests-views (like LPP and AAP). It also indicts ASP, which enfranchises the superrich traveler in all the countries she visits. ${ }^{19}$ Second, and more fundamentally, we might reject the 'transmitting injustice'-issue as a problem for AAP, ASP, and LPP qua ideal principles of democratic inclusion in the first place. We might understand democracy (including its inclusion principle) in a 'thick' or 'thin' sense. On the thick view, democracy is meant to incorporate other values such as justice. Injustice-transmission is then indeed problematic: inclusion principles that undermine values that democracy is meant to incorporate must be revised. On the thin view, however, democracy does not incorporate other values, and it might be overridden for the sake of promoting them. When they conflict, we might simply insist on balancing our inclusion-principle against justice (or find some other method of adjudication). As I read them, proponents of AAP or ASP do largely favor the thin view. ${ }^{20}$ They would thus presumably reject the problem, as I do.

\section{Conclusion}

This article has defended a refined version of the affected interests-view of voting rights. I believe LPP improves upon the most prominent principles in the literature - AAP and ASP - by straightforwardly accommodating the intuition against enfranchising tourists and (small) children. Although this does not settle the case for LPP, I hope to have done enough to establish it as an alternative that warrants further consideration.

Acknowledgements Earlier versions of this paper have been presented at: the Half-Baked Lunch Seminar, University Center for Human Values, Princeton University; the Tuesday Seminar, Department of Political Science, University of Oslo; the 2016 APSA Annual Meeting in Philadelphia; the Practical Philosophy Working Group, Department of Philosophy, University of Oslo; the 2016 annual meeting of the Nordic Network in Political Theory in Oslo; and the 1st Workshop on Political Equality and Voting, Department of Learning and Philosophy, Aalborg University. I am grateful to the participants at these events for helpful discussions. Special thanks to Lucia Rafanelli, Shuk Ying Chan, Sune Lægaard, Ludvig Beckman, Robert Huseby, Sam Gray, Jakob Elster, Frej Klem Thomsen, Göran Duus-Otterström, Franco Trivigno, Caj Strandberg, Knut Olav Skarsaune, Jason Brennan, Jørn Sønderholm, Jens Damgaard Thaysen, Andreas Albertsen, Jakob Mainz, and two anonymous reviewers for Ethical Theory and Moral Practice, whose comments have helped me significantly improve this article

Funding Information This project has received funding from the European Union's Horizon 2020 research and innovation programme under grant agreement No 792263.

Disclaimer This article reflects only the author's view. The European Commission is not responsible for any use that may be made of the information it contains.

Open Access This article is distributed under the terms of the Creative Commons Attribution 4.0 International License (http://creativecommons.org/licenses/by/4.0/), which permits unrestricted use, distribution, and reproduction in any medium, provided you give appropriate credit to the original author(s) and the source, provide a link to the Creative Commons license, and indicate if changes were made.

\footnotetext{
${ }^{19}$ I concede that some might find it counterintuitive that we have even pro tanto reason to enfranchise people like the superrich traveler in all the countries she visits (or perhaps someone who, as an anonymous reviewer writes, "[suddenly decides] to go on a multi-year global adventure to find meaning in her life"). At any rate, LPP will fare at least equally well as its two rivals here. If anything, LPP will enfranchise the traveler on fewer decisions than AAP and ASP. While the whole set of laws in each country that the traveler visits will presumably subject her or possibly affect her interests, it seems plausible to expect that only a subset of the country's laws will relevantly affect her autonomy.

${ }^{20}$ See e.g. López-Guerra (2005: 225, 223) and Beckman (2009: 33).
} 


\section{References}

Abizadeh A (2008) Democratic theory and border coercion: no right to unilaterally control your own borders. Political Theory 36:37-65

Arrhenius G (2005) The boundary problem in democratic theory. In: Tersman F (ed) Democracy unbound: basic explorations. Filosofiska institutionen, Stockholms Universitet, Stockholm

Arrhenius G (2018) The democratic boundary problem reconsidered. Ethics Polit Soc 1:89-122

Baker A (2016) Simplicity. In: Zalta EN (ed) Stanford encyclopedia of philosophy. https://plato.stanford. edu/archives/win2016/entries/simplicity/

Bauböck R (2009) The rights and duties of external citizenship. Citizsh Stud 13:475-499

Beckman L (2009) Frontiers of democracy. The right to vote and its limits. Palgrave Macmillan, London

Betzler M (2015) Enhancing the capacity for autonomy: what parents owe their children to make their lives go well. In: Baggatini A, Macleod C (eds) The nature of children's well-being. Springer, Dordrecht, pp 65-84

Brighouse H, Fleurbaey M (2010) Democracy and proportionality. J Polit Philos 18:137-155

Buss S, Westlund A (2018) Personal autonomy. In: Zalta EN (ed) Stanford encyclopedia of philosophy. https://plato.stanford.edu/archives/spr2018/entries/personal-autonomy

Christiano T (1996) The rule of the many: fundamental issues in democratic theory. Westview Press, Boulder, $\mathrm{CO}$

Elster J (2011) How outlandish can imaginary cases be? J Appl Philos 28:241-258

Erman E (2014) The boundary problem and the ideal of democracy. Constellations 21:535-546

Goodin RE (2007) Enfranchising all affected interests, and its alternatives. Philos Public Aff 25:40-68

Goodin RE (2016) Enfranchising all subjected, worldwide. Int Theory 8:365-389

Lampert J (2015) Democratic inclusion and the governance of immigration. Soc Theory Pract 41:51-76

López-Guerra C (2005) Should expatriates vote? J Polit Philos 13:216-234

López-Guerra C (2012) Enfranchising minors and the mentally impaired. Soc Theory Pract 38:115-138

López-Guerra C (2014) Democracy and disenfranchisement: the morality of electoral exclusions. Oxford University Press, Oxford

Miklosi Z (2012) Against the principle of all-affected interests. Soc Theory Pract 38:483-503

Miller D (1995) On nationality. Clarendon Press, Oxford

Mullin A (2007) Children, autonomy, and care. J Soc Philos 38:536-553

Owen D (2010) Resident aliens, non-resident citizens and voting rights. In: Calder G, Cole P, Seglow J (eds) Citizenship acquisition and national belonging. Palgrave Macmillan, London, UK, pp 52-73

Owen D (2012) Constituting the polity, constituting the demos: on the place of the all affected interests principle in democratic theory and in resolving the democratic boundary problem. Ethics Global Polit 5:129-152

Rawls J (1999) A theory of justice: revised edition. Harvard University Press, Cambridge, MA

Raz J (1986) The morality of freedom. Oxford University Press, Oxford

Rehfeld A (2011) The child as democratic citizen. Ann Am Acad Pol Soc Sci 633:141-166

Stilz A (2013) Occupancy rights and the wrong of removal. Philos Public Aff 41:324-356

Waldron J (2012) Democracy. In: Estlund D (ed) The Oxford handbook of political philosophy. Oxford University Press, Oxford, pp 187-203

Whitt MS (2017) Felon disenfranchisement and democratic legitimacy. Soc Theory Pract 43:283-311

Publisher's Note Springer Nature remains neutral with regard to jurisdictional claims in published maps and institutional affiliations. 